\title{
Regulation of Sensorimotor Gating of the Startle Reflex by Serotonin 2A Receptors: Ontogeny and Strain Differences
}

\author{
Marjan Farid, Zoe A. Martinez, Mark A. Geyer, Ph.D., and Neal R. Swerdlow, M.D., Ph.D.
}

Sensorimotor gating of the startle reflex can be assessed via measures of prepulse inhibition (PPI), which is the reduction in startle magnitude when the startling stimulus is preceded immediately by a weak prepulse. PPI is reduced in humans with specific neuropsychiatric disorders and in rats after treatment with certain classes of drugs, including serotonin (5-HT) agonists. Because of the relative loss of PPI in inherited, neurodevelopmental disorders such as schizophrenia, there is great interest in understanding the inherited and developmental features of the neurochemical regulation of PPI in animals. In the present study, PPI was disrupted significantly by the 5-HT2A agonist 2,5-

dimethoxy-4 iodopheny-lisopropylamine (DOI) in Sprague Dawley (SDH) and Wistar rat strains (WH). While it was demonstrated that the DOI effects in SDH rats reflected an unequivocal disruption of sensorimotor gating, in WH rats, reduced PPI was observed in the context of a trend for a DOI-induced reduction in startle magnitude. This effect of DOI in SDH rats was evident at the earliest date tested (17 days of age) in male pups, but was not statistically significant in female pups. Thus, the regulation of sensorimotor gating by 5-HT2A receptor stimulation in rats may exhibit subtle differences across strains, and within SDH rats, between sexes. Most importantly, the $5-\mathrm{HT} 2 \mathrm{~A}$ regulation of sensorimotor gating in male $\mathrm{SDH}$ rats is a "phenotype" that is expressed very early in life, and is sustained through adulthood.

[Neuropsychopharmacology 23:623-632, 2000] (c) 2000 American College of Neuropsychopharmacology. Published by Elsevier Science Inc.
KEY WORDS: Prepulse inhibition; Schizophrenia; Sensorimotor regulation; Serotonin; Startle; Strain differences

Prepulse inhibition (PPI) is the reduction in startle reflex magnitude when a startling stimulus is preceded by a weak prestimulus. PPI is diminished in patients with schizophrenia (Braff et al. 1978; Grillon et al. 1992; Bolino et al. 1994), obsessive compulsive disorder (Swerdlow et al. 1993), Huntington's disease (Swerd-

From the Department of Psychiatry, University of California, San Diego, La Jolla, CA.

Address correspondence to: Neal R. Swerdlow, M.D., Ph.D., Department of Psychiatry, 0804, UCSD School of Medicine, 9500 Gilman Dr., La Jolla, CA 92093-0804.

Received 17 January 2000; revised 20 April 2000; accepted 16 June 2000. low et al. 1995), nocturnal enuresis and attention deficit disorder (Ornitz et al. 1992), and Tourette Syndrome (Castellanos et al. 1996). These disorders are all marked by an inability to inhibit, or "gate" irrelevant information in sensory, motor, or cognitive domains. In schizophrenia, this loss of gating is conceptually linked to processes responsible for sensory flooding and cognitive fragmentation (McGhie and Chapman 1961).

In the rat, disruption of PPI occurs after acute administration of dopamine (DA) agonists (Swerdlow et al. 1986; Mansbach et al. 1988), NMDA antagonists (Mansbach and Geyer 1989a, 1991), or serotonin (5-HT) agonists (Mansbach et al. 1989b; Rigdon and Weatherspoon 1992; Kehne et al. 1992; Sipes and Geyer 1994). Studies in rats of the neural basis for drug effects on PPI may provide a means to further understand the pathophysiology of neuropsychiatric disorders characterized by deficits in 
sensorimotor gating (Swerdlow et al. 1994; Swerdlow and Geyer 1998). The present studies were designed to assess two aspects of the regulation of PPI by 5-HT2A receptors in rats: 1 ) the sensitivity to the PPI-disruptive effects of the 5-HT2A receptor agonist, 2,5-dimethoxy-4 iodopheny-lisopropylamine (DOI), in Wistar/Harlan ("WH") vs. Sprague Dawley/Harlan ("SDH") rats; and 2) the developmental time-course of the PPI-disruptive effects of DOI in male and female SDH pups.

The regulation of PPI by brain 5-HT receptors is a topic of particular interest based on the 5-HT receptorblocking properties of novel atypical antipsychotics, such as clozapine, olanzapine, and quetiapine. In rats, PPI is disrupted by 5-HT agonists, and these effects are opposed by 5-HT antagonists. For example, the PPI disruptive effects of the direct 5-HT2A receptor agonist DOI are prevented by the putative novel antipsychotic and 5-HT2A antagonist M100907 (Sipes and Geyer 1995b). Other 5-HT receptor agonists have also been shown to disrupt PPI, including 5-HT releasers (Mansbach et al. 1989b; Kehne et al. 1996; Martinez and Geyer 1997), direct 5-HT1A agonists such as 8-OH-DPAT (Rigdon and Weatherspoon 1992; Sipes and Geyer 1994, 1995a), and direct 5-HT1B agonists such as RU 24969 (Sipes and Geyer 1996; Dulawa et al. 1997). Experimental paradigms have been used to elucidate features of the serotonergic regulation of PPI, ranging from the role of specific receptor subtypes in this process (Sipes and Geyer 1994), to their neuroanatomical localization (Sipes and Geyer 1995a; 1997).

Given the clear genetic transmission of several disorders characterized by impaired sensorimotor gating, there is great interest in understanding the genetics of PPI, and of its regulation by 5-HT and other neurotransmitters. Previous studies have demonstrated significant differences in the sensitivity to drug-induced PPI deficits between rat strains, and within strains-between rat suppliers. For example, differences in sensitivity to the PPI-disruptive effects of the DA agonist apomorphine have been reported between Wistar vs. Sprague Dawley strains, and between Harlan, Charles River, and Bantin-Kingman suppliers of Sprague Dawley rats (Rigdon 1990; Varty and Higgins 1994; Swerdlow et al. 1998; Kinney et al. 1999). No such across-strain comparisons have been reported for the sensitivity of PPI to 5-HT2A receptor agonists, such as DOI, although Hitchcock et al. (1999) reported greater sensitivity to these DOI effects in Harlan vs. Charles River substrains of Sprague Dawley rats.

Because of the high degree of genetic homology across rat strains and substrains, the presence or absence of differences in a particular phenotype (e.g., 5-HT2A agonist sensitivity in PPI measures) may provide direction and a valuable target for genetic analyses. Such strain- and substrain analyses of drug effects on PPI may be particularly informative about candidate genes for several neuropsychiatric disorders; identifying the physiological substrates responsible for these genetic differences in drug sensitivity may suggest specific strategies for developing novel treatments of these disorders.

The PPI-disruptive effects of the hallucinogenic 5-HT2A agonist, DOI, have been previously demonstrated in adult rats (Sipes and Geyer 1994, 1995b; Hitchcock et al. 1999). No published studies have reported this DOI effect in younger rats. PPI disruption by DOI in juvenile rats would suggest that the brain substrates responsible for this drug effect are functional at an early stage of brain development and are not dependent on adult patterns of forebrain innervation, puberty, or other processes of later maturation. Furthermore, sensitivity to the PPI-disruptive effects of DOI in juvenile rats would allow for a more efficient characterization of this phenotype in future studies designed to explore the genetic regulation of PPI. In the present study, we assessed the sensitivity of adult SDH and WH rats to the PPI-disruptive effects of DOI, and also examined these drug effects in 17-day old male and female SDH pups, at the earliest time point that PPI could be studied reliably.

\section{METHODS}

\section{Experimental Animals}

A total of 41 male and 44 female SDH rat pups weighing $29-45 \mathrm{~g}$, and $34 \mathrm{SDH}$ and $41 \mathrm{WH}$ adult male rats weighing 250-300 g were used in these experiments. Studies in adults were limited to male rats, based on findings of estrous cyclicity of the PPI-disruptive effects of apomorphine in adult female rats (Koch 1998). To closely match the rearing environments of SDH pups, timed pregnant female rats were housed individually, and pups were housed with their mothers until 5-7 days after birth; at that time rat pups were sexed and redistributed so that each litter was approximately the same size and contained an equal number of male and female pups. Adult male rats were housed in same-sex rooms in groups of two or three. A reversed 12-hr light/dark cycle was used (lights on at 1900, off at 0700) for at least one week prior to testing. All testing and drug administration occurred between $1000 \mathrm{hr}$ and $1700 \mathrm{hr}$. Rats were handled prior to any procedures to minimize stress during behavioral testing, and were given ad libitum access to food and water except during behavioral testing.

\section{Drugs}

DOI HCl (Sigma/RBI) (saline vehicle, 0.1, 0.25, 0.5, or $1.0 \mathrm{mg} / \mathrm{kg}, n=8-9 /$ dose) was administered subcutaneously (s.c.) in a volume of $1 \mathrm{ml} / \mathrm{kg}, 10$ minutes prior to startle testing. 


\section{Apparatus}

All startle experiments utilized four startle chambers (SR-LAB; San Diego Instruments, San Diego, CA) housed in a sound-attenuated room with a $60 \mathrm{~dB}$ ambient noise level. For adult rats, each chamber consisted of a Plexiglas cylinder $8.7 \mathrm{~cm}$ in internal diameter resting on a $12.5 \times 25.5 \mathrm{~cm}$ Plexiglas stand. For rat pups, each startle chamber consisted of a smaller Plexiglas cylinder $3.75 \mathrm{~cm}$ in internal diameter resting on a $12.5 \times$ $25.5 \mathrm{~cm}$ Plexiglas stand. Acoustic stimuli and background noise were presented via a Radioshack Supertweeter mounted $24 \mathrm{~cm}$ above the Plexiglas cylinder. Startle magnitude was detected and recorded as transduced cylinder movement via a piezoelectric device mounted below the Plexiglas stand. Acoustic stimulus intensities and response sensitivities were calibrated (using an SR-LAB Startle Calibration System) to be nearly identical in each of the four startle chambers (maximum variability $<1 \%$ of stimulus range and $<5 \%$ of response ranges).

Response sensitivities were calibrated for adult and pup chambers separately and recalibrated each time the chambers were changed, always within the $<5 \%$ response range. Chambers were also balanced across all experimental groups. Sound levels were measured and calibrated with a sound level meter (Quest electronics, Oconomowoc, WI), A scale (relative to $20 \mu \mathrm{N} / \mathrm{M} 2$ ), with microphone placed inside the Plexiglas cylinder.

\section{Testing Procedures}

In the testing apparatus, reliable measures of startle could first be obtained in pups at 14 days of age. At 14 days of age, different groups of rat pups were exposed to a brief "matching" startle session. Rat pups were placed in a startle chamber, and exposed to 5 minutes of $70 \mathrm{~dB}$ background noise followed by 17 PULSE trials of $40 \mathrm{~ms} 120 \mathrm{~dB}$ noise bursts ("PULSE ALONE") and 5 PREPULSE + PULSE trials consisting of a $20 \mathrm{~ms} 82 \mathrm{~dB}$ (12 dB above background) prepulse followed $100 \mathrm{~ms}$ by a $120 \mathrm{~dB}$ pulse (onset to onset). Adult rats were exposed to this "matching" session 3-7 days prior to testing. Consistent with a number of previous reports (Martinez and Geyer 1997; Martinez et al. 2000; Swerdlow et al. 1998), data from this session were used to assign rat pups and adults to balanced dose groups according to their average PULSE ALONE startle magnitude.

Behavioral testing continued three days after the "matching" session for pups, and 3-7 days after the matching session for adults. Seventeen-day-old rat pups were brought to the laboratory in their home cages, with their mothers to minimize stress before and after testing. Adult rats were brought to the laboratory in separate cages. Each test session was approximately 15 minutes long and consisted of 5 minutes of $70 \mathrm{~dB}$ background followed by five trial types: PULSE ALONE noise bursts, PREPULSE trials (20 ms noise bursts 5,10 , or $15 \mathrm{~dB}$ above background followed $100 \mathrm{~ms}$ by a PULSE), and NoStim trials (stabilimeter recordings obtained when no stimulus was presented). The session consisted of initial and final Blocks of 3-4 PULSE trials each (Blocks 1 and 4, respectively), separated by two blocks that included 8 PULSE trials and 15 PREPULSE trials each (prepulse trials divided equally among 5, 10, and $15 \mathrm{~dB}$ prepulse intensities) (Blocks 2 and 3, respectively); NoStim trials were presented throughout the session in a pseudorandomized order.

For "NoStim" trials, stabilimeter readings were recorded during periods where no stimulus was presented; these trials were used to assess gross motor activity during the test session, but were not included in the calculation of intertrial intervals. Startle reflex habituation can be assessed in a variety of ways; in the present study, reflex "habituation" was determined based on the change in startle magnitude from the initial to the final block of PULSE trials (Block 1 vs. Block 4). Using this design, PPI was measured during a portion of the session (Blocks 2 and 3 ) in which startle magnitude was relatively constant.

\section{Data Analysis}

PPI was calculated as a percent reduction in startle magnitude on PREPULSE trials compared to PULSE trials. Any drug effects on \%PPI prompted separate analyses to assess the relationship of these effects to drug-induced changes in startle magnitude on PULSE and PREPULSE trials. An important issue raised by Kinney et al. (1999) and in many previous reports (e.g., Davis et al. 1990; Mansbach et al. 1988; Swerdlow and Geyer 1993) relates to the fact that drug-induced changes in startle magnitude-potentially independent of prepulse effects-can influence the calculation of \%PPI.

Unequivocal changes in sensorimotor gating occur when the reflex-inhibiting effects of prepulses are modified, independent of changes in startle magnitude on PULSE trials. Thus, for each experiment, data were assessed to determine whether drug-induced changes in the calculated amount of \%PPI reflected unambiguous changes in sensorimotor gating per se. All startle data were analyzed using an analysis of variance (ANOVA) with drug treatment as between-subject factors and trial block and trial type as within-subject repeated measures. All post hoc comparisons were conducted using the Tukey-Kramer test. Alpha was set at 0.05 .

\section{Treatment and Test Schedule}

Experiment 1: Effects of DOI on Startle Measures in Adult Male SDH and WH Rats. Adult SDH male rats $(n=34)$ and WH male rats $(n=41)$ were tested 10 min- 
utes after s.c. administration of DOI (saline vehicle, 0.1, $0.25,0.5,1.0 \mathrm{mg} / \mathrm{kg} ; n^{\prime} \mathrm{s}=7,7,7,6,7$ for SDH and $n^{\prime} \mathrm{s}=$ $9,8,8,8,8$ for $\mathrm{WH}$ ).

Experiment 2: Effects of DOI on Startle Measures Across Development. Rat pups $(n=85)$ were tested on postnatal day 17, 10 minutes after s.c. administration of DOI (saline vehicle, $0.1,0.25,0.5,1.0 \mathrm{mg} / \mathrm{kg} ; n^{\prime} \mathrm{s}=9$, $8,8,8,8$ for males and $n^{\prime} \mathrm{s}=9,9,9,8,9$ for females, respectively).

\section{RESULTS}

\section{Experiment 1: Effects of DOI on Startle Measures in Adult Male SDH and WH Rats}

PPI. DOI significantly reduced PPI in both SDH and WH rats (Figure 1). ANOVA with dose and strain as between subject factors revealed a significant effect of DOI dose $(\mathrm{F}=8.12, \mathrm{df}=4,65, p<.0001)$ and strain $(\mathrm{F}=$
9.04, $\mathrm{df}=1,65, p<.004)$, but no significant strain $\times$ DOI interaction $(\mathrm{F}<1)$. There was a significant effect of prepulse intensity $(\mathrm{F}=78.63, \mathrm{df}=2,130, p<.0001)$ and a significant interaction of prepulse intensity $\times$ DOI $(\mathrm{F}=$ $2.71, \mathrm{df}=8,130, p<.01)$. There was no significant effect of trial block $(\mathrm{F}=2.14 \mathrm{df}=1,65, \mathrm{~ns})$, but there was a significant interaction of block $\times$ DOI $(\mathrm{F}=3.29, \mathrm{df}=$ $4,65, p<.02)$. There were no other significant 2- or 3-way interactions.

The significant effect of strain reflected lower basal (i.e., post-vehicle) levels of PPI in WH rats compared to $\mathrm{SDH}$ rats (mean (SEM) \%PPI: $\mathrm{SDH}=79.2(2.68)$ vs. $\mathrm{WH}=$ 58.9 (3.43); $\mathrm{F}=5.49, \mathrm{df}=1,14, p<.035)$. Post hoc comparisons also confirmed significant PPI-disruptive effects of DOI in both SDH ( $\mathrm{F}=6.00, \mathrm{df}=4,29, p<.002)$ and $\mathrm{WH}$ rats $(\mathrm{F}=3.40, \mathrm{df}=4,36, p<.02)$; these effects were significant in SDH rats treated with $0.25,0.5$, or 1.0 $\mathrm{mg} / \mathrm{kg}$ doses of DOI ( $p<.05$, all comparisons; Tukey test); in WH rats, PPI was significantly reduced only at the $1.0 \mathrm{mg} / \mathrm{kg}$ dose.

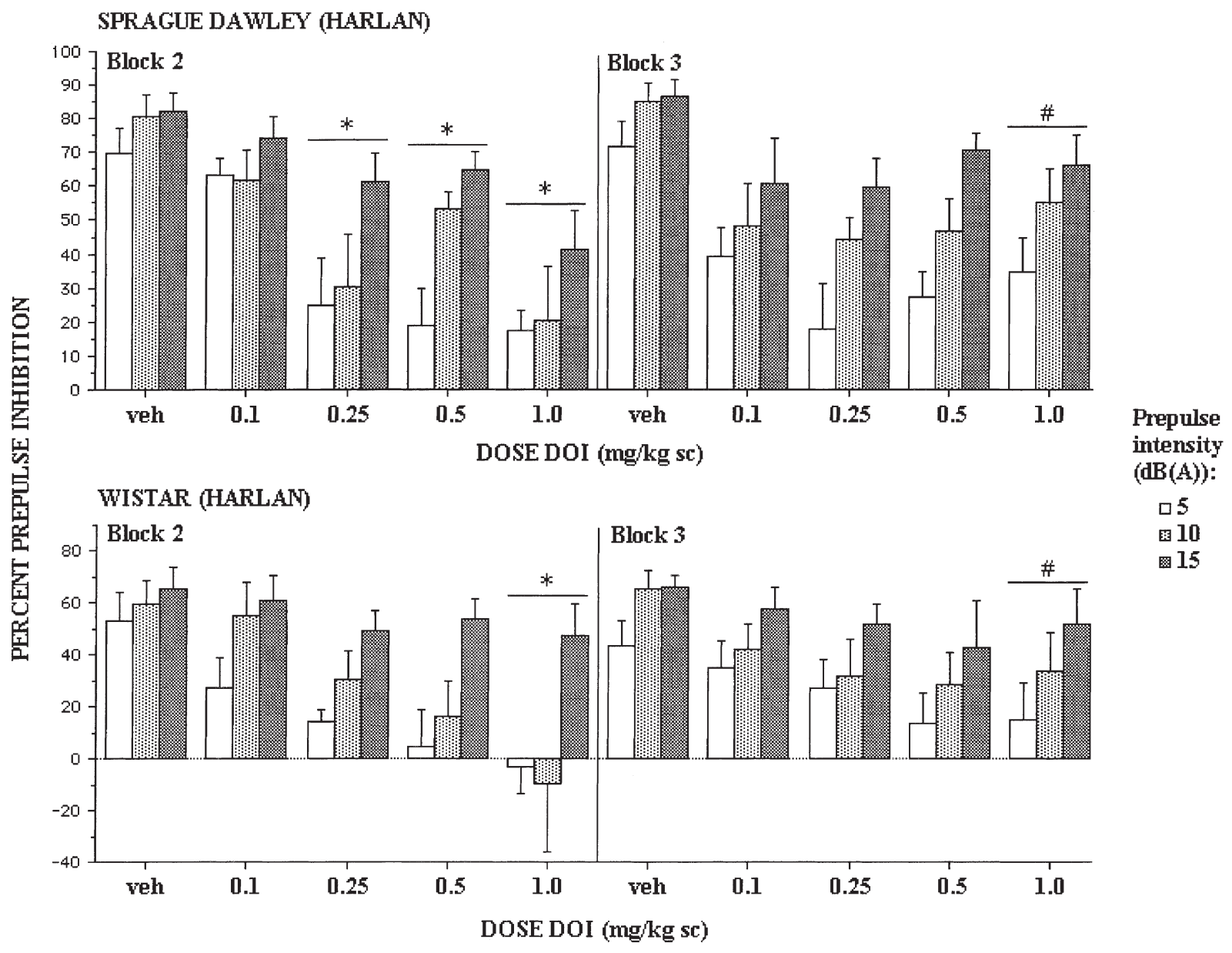

Figure 1. Effects of DOI on PPI in SDH and WH adult male rats. DOI produced a reduction in PPI in SDH and WH rats. This reduction was statistically significant at the $0.25,0.5$, and $1.0 \mathrm{mg} / \mathrm{kg}$ doses for $\mathrm{SDH}$ rats and significant at the $1.0 \mathrm{mg} / \mathrm{kg}$ dose for the WH rats $\left({ }^{*} p<.05\right.$ vs. vehicle by Tukey-Kramer post hoc comparison, following significant main effects of dose by ANOVA). A significant reduction in the effects of $1.0 \mathrm{mg} / \mathrm{kg}$ DOI was noted in Block 2 vs. 3 (\#significant effect of block for this dose, $p<.05)$. 
Based on the significant interaction of DOI $\times$ prepulse intensity, inspection of DOI effects across prepulse intensities revealed significant effects only for $5 \mathrm{~dB}(\mathrm{~F}=10.96, \mathrm{df}=4,65, p<.005)$ and $10 \mathrm{~dB}$ prepulse intensities $(\mathrm{F}=7.20, \mathrm{df}=4,65, p<.0001)$, but only a trend of this effect for $15 \mathrm{~dB}$ prepulse intensity ( $\mathrm{F}=$ $2.39, \mathrm{df}=4,65, p=.06)$. Based on the significant block $\times$ DOI interaction, post hoc comparisons revealed a doserelated diminution of the DOI-disruption of PPI in Block 2 for both rat strains. This effect was most evident with the highest dose of DOI $(1 \mathrm{mg} / \mathrm{kg}$; significant effect of block, $\mathrm{F}=6.54, \mathrm{df}=1,13, p<.025$; no significant effect of strain or strain $\times$ block interaction), and was not evident at doses of 0.25 or $0.1 \mathrm{mg} / \mathrm{kg}$ (Figure 1).

We examined whether the early (Block 2 ) effects on PPI reflected changes in sensorimotor gating per se, i.e., a reduction in the ability of the prepulse to inhibit the startle reflex, independent of changes in startle on PULSE trials. Examination of the data (Figure 2) revealed that on PULSE trials, DOI caused a dose-dependent reduction in startle magnitude in $\mathrm{WH}$ rats, but had no consistent effect on PULSE magnitude in SDH rats (see analyses below). In contrast, on PREPULSE trials, DOI clearly increased startle magnitude in SDH rats $(\mathrm{F}=3.15, \mathrm{df}=$ $4,29, p<.03)$, but not in $\mathrm{WH}$ rats $(\mathrm{F}<1)$. Thus, while DOI caused a reduction in \%PPI in both SDH and WH strains, the present study detected an unequivocal reduction in sensorimotor gating only in SDH rats.

One post hoc strategy for understanding the impact of DOI-induced decreases in startle magnitude on changes in PPI in WH rats is to assess PPI among WH dose groups that are "matched" for levels of startle magnitude. Rats were identified from vehicle, $0.25,0.5$, and $1.0 \mathrm{mg} / \mathrm{kg}$ dose groups with comparable Block 2 mean startle magnitudes (mean $(\mathrm{SEM})=208.59$ (53.13), 200.39 (35.77), 237.42 (38.31), and 196.59 (23.89), respectively). Compared to vehicle-treated rats, among these matched groups, PPI was significantly reduced by 0.25 , 0.5 , and $1.0 \mathrm{mg} / \mathrm{kg}$ DOI (F $=4.67,4.68$, and 6.24, respectively; $p^{\prime}$ s $\left.<.05\right)$. Thus, while DOI appears to have both startle- and PPI-reducing effects in WH rats, there is some evidence that these effects are separable.
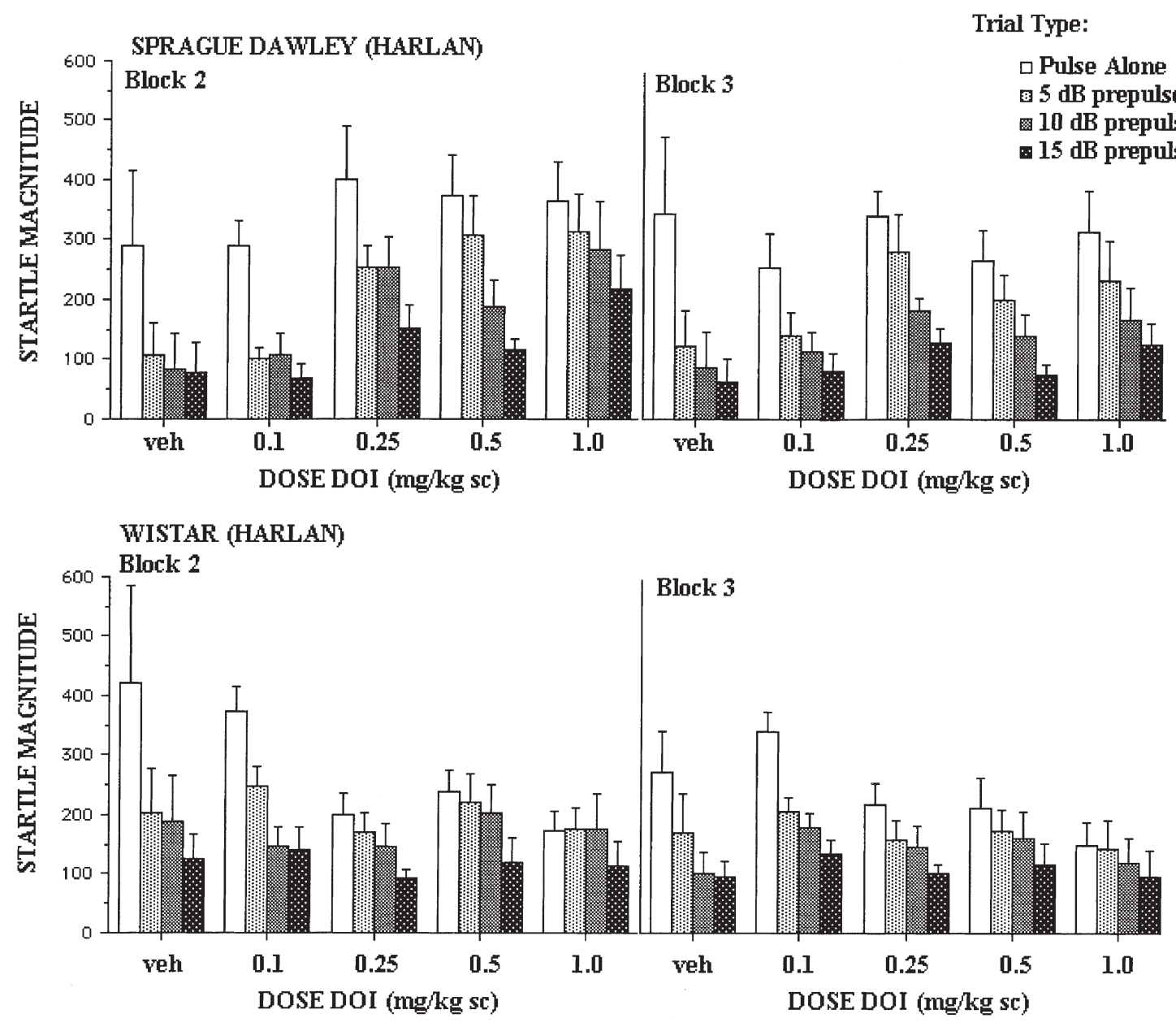

Figure 2. Effects of DOI on raw startle magnitude on PULSE and PREPULSE trials. DOI significantly increased startle magnitude on PREPULSE trials in SDH, but not WH rats; the calculated reduction of \%PPI in WH rats appeared to reflect a reduction in startle magnitude on PULSE trials. Error bars represent SEM. 
Table 1. Startle magnitude, habituation, and NO STIM activity in adult SDH and WH rats

\begin{tabular}{|c|c|c|c|c|c|c|c|}
\hline \multirow{2}{*}{$\begin{array}{l}\text { Dose DOI } \\
(\mathrm{mg} / \mathrm{kg})\end{array}$} & \multirow[b]{2}{*}{$N$} & \multicolumn{2}{|c|}{$\begin{array}{l}\text { Startle Magnitude } \\
\text { (mean (SEM)) }\end{array}$} & \multicolumn{2}{|c|}{$\begin{array}{l}\text { Habituation (startle magnitude } \\
\text { (mean (SEM)) in Blocks } 1 \text { and } 4 \text { ) }\end{array}$} & \multirow{2}{*}{$\begin{array}{c}\% \\
\text { Habituation }\end{array}$} & \multirow{2}{*}{$\begin{array}{c}\text { NO STIM } \\
(\text { mean }(\text { SEM)) }\end{array}$} \\
\hline & & Block 2 & Block 3 & Block 1 & Block 4 & & \\
\hline \multicolumn{8}{|l|}{ SDH rats } \\
\hline Veh & 7 & $289.11(127.03)$ & 343.04 (128.08) & $1004.86(228.27)$ & 364.24 (114.2) & 64.98 & $0.002(.002)$ \\
\hline 0.10 & 7 & $289.61(41.98)$ & $253.14(58.25)$ & 999.21 (122.72) & $219.43(42.54)$ & 74.95 & $0.480(.302)$ \\
\hline 0.25 & 7 & $401.20(87.05)$ & 341.59 (39.82) & $1031.32(181.52)$ & 337.81 (78.65) & 54.37 & $0.828(.434)$ \\
\hline 0.50 & 6 & $373.81(67.10)$ & $266.67(48.36)$ & $861.04(208.06)$ & $299.00(37.00)$ & 51.64 & $0.972(.323)$ \\
\hline 1.00 & 7 & 363.57 (65.67) & $313.38(68.72)$ & $576.93(122.31)$ & $309.48(65.23)$ & 43.98 & $1.221(.352)$ \\
\hline \multicolumn{8}{|l|}{ WH rats } \\
\hline Veh & 9 & $420.99(165.14)$ & 271.57 (70.07) & 761.50 (105.54) & 317.85 (95.05) & 61.75 & $0.036(.021)$ \\
\hline 0.10 & 8 & $372.92(41.20)$ & 340.84 (32.29) & 779.63 (147.27) & $210.67(36.73)$ & 63.8 & $0.848(.413)$ \\
\hline 0.25 & 8 & 200.39 (35.77) & $217.22(35.69)$ & $582.00(92.97)$ & $164.58(34.67)$ & 70.97 & $0.886(.496)$ \\
\hline 0.50 & 8 & $237.42(38.31)$ & $211.70(50.99)$ & 662.50 (132.37) & $213.92(39.96)$ & 61.57 & $0.928(.429)$ \\
\hline 1.00 & 8 & $174.20(30.48)$ & $148.80(39.95)$ & $470.09(78.74)$ & $142.96(39.57)$ & 67.93 & $1.414(.588)$ \\
\hline
\end{tabular}

Startle Magnitude and Habituation. ANOVA with dose of DOI and strain as between subject factors revealed no significant effect of strain $(\mathrm{F}=2.03, \mathrm{df}=1,65$, ns) or DOI dose on startle magnitude during Blocks 2 and $3(\mathrm{~F}=0.42, \mathrm{df}=4,65, \mathrm{~ns})$ and no significant strain $\times$ DOI interaction $(\mathrm{F}=1.38, \mathrm{df}=4,65, \mathrm{~ns})$ (Table 1$)$. However, examination of the data revealed a clear trend towards a dose-dependent reduction of startle magnitude on PULSE trials in WH rats, but not SDH rats.

Habituation was evident both in the significant reduction in pulse alone startle magnitude between Blocks 1 and $4(\mathrm{~F}=159.5, \mathrm{df}=1,65, p<.0001)$, as well as in the effect of trial block on pulse alone startle magnitude during the course of PPI testing (Blocks 2 and 3 ) $(\mathrm{F}=5.94, \mathrm{df}=1,65, p<.02)$ (Table 1$)$. For Blocks 1 and 4 , there was a significant main effect of strain $(F=8.65$, $\mathrm{df}=1,65, p<.005)$, reflecting lower startle magnitude in $\mathrm{WH}$ vs. SDH rats, but there was no strain difference in habituation or its sensitivity to DOI, based on a lack of significant interactions of strains $\times$ blocks $\times$ DOI (all ns).

NoStim Activity. NoStim measures were used to assess drug effect on gross motor activity, but cannot be considered comparable to more sensitive measures of locomotion or stereotyped behavior. DOI significantly increased gross motor activity in both strains of rat (Table 1). ANOVA with strain and dose as between subject factors revealed a significant effect of DOI $(\mathrm{F}=2.84, \mathrm{df}=$ $4,65, p<.035)$, no significant effect of strain $(\mathrm{F}<1)$, and no significant interaction of strain $\times$ DOI $(F<1)$, or other interactions.

\section{Experiment 2: Effects of DOI on Startle Measures Across Development}

These studies were conducted to determine whether the "phenotype" of DOI-disruption of sensorimotor gating is expressed in juvenile as well as adult rats.
PPI. As previously reported for adult male rats, DOI in pups caused a dose-related reduction of PPI in Block 2, but a "U-shaped" dose-relationship in Block 3 . ANOVA with dose and sex as between subject factors revealed no significant effect of $\operatorname{sex}(\mathrm{F}=1.04, \mathrm{df}=1,75$, ns) or DOI dose $(\mathrm{F}<1)$, and no sex $\times$ dose interaction $(\mathrm{F}<1)$. There was a significant effect of block $(\mathrm{F}=5.71$, $\mathrm{df}=1,75, p<.02)$ and prepulse intensity $(\mathrm{F}=117.04, \mathrm{df}=$ $2,150, p<.0001)$, and a significant interaction of sex $\times$ DOI $\times$ prepulse intensity $(\mathrm{F}=2.36, \mathrm{df}=8,150, p<$ .025), but no other significant interactions.

To understand the basis of this 3-way interaction, ANOVAs performed separately on male and female pups revealed no significant main effect of DOI in female pups $(\mathrm{F}<1)$, but a significant interaction of DOI $\times$ intensity $(\mathrm{F}=2.50, \mathrm{df}=8,78, p<.02)$ (Figure 3). Post hoc comparisons revealed no significant effect of DOI at any of the three prepulse intensities; only a trend $(p<$ .1) was observed for reduced PPI with $10 \mathrm{~dB}$ prepulses. Based on the apparent time-dependent DOI effects, data were inspected in Block 2 alone, but revealed no significant effect of DOI $(F<1)$ or DOI $\times$ intensity interaction $(\mathrm{F}=1.57, \mathrm{df}=8,78, \mathrm{~ns})$.

DOI significantly reduced PPI early in the test session for male pups, at the 10 and $15 \mathrm{~dB}$ prepulse intensities. ANOVA of Block 2 revealed no significant main effect DOI $(\mathrm{F}=2.03, \mathrm{df}=4,36, \mathrm{~ns})$, but a significant effect of prepulse intensity ( $\mathrm{F}=36.07, \mathrm{df}=2,72, p<.0001)$, and a near-significant interaction of DOI $\times$ prepulse intensity ( $\mathrm{F}=2.06, \mathrm{df}=8,72, p=.051)$. Post hoc comparisons revealed significant PPI-disruptive effects of DOI dose for $10 \mathrm{~dB}$ prepulses $(\mathrm{F}=2.75, \mathrm{df}=4,36, p<.05)$ and $15 \mathrm{db}$ prepulses $(\mathrm{F}=2.63, \mathrm{df}=4,36, p=.05)$.

The failure to detect $\mathrm{DOI}$ effects for five $\mathrm{dB}$ prepulses $(F<1)$ reflected the near-zero values of PPI for this prepulse intensity (mean (SEM) \%PPI for vehicletreated rats at this intensity $=4.41(6.55))$. Analysis of raw startle magnitude confirmed a reduction in sensorimotor gating-i.e., increased startle magnitude on 


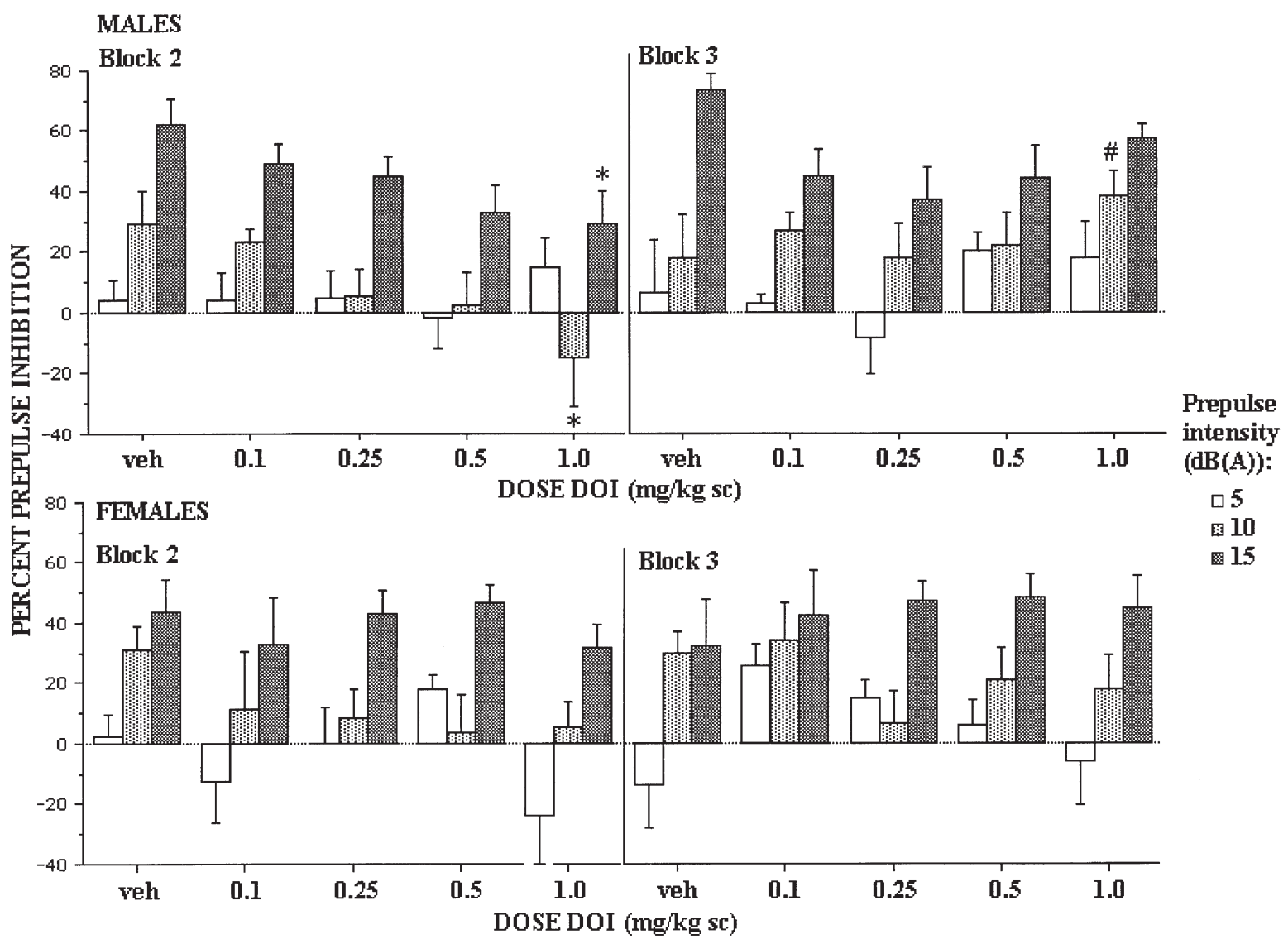

Figure 3. Effects of DOI on PPI in SDH male and female pups. DOI produced a reduction in PPI in male, but not female pups. This reduction in males was statistically significant for 10 and $15 \mathrm{~dB}$ prepulse conditions in Block 2, vehicle vs. $1.0 \mathrm{mg} /$ $\mathrm{kg}$ DOI ( ${ }^{*} p<.05$ by post hoc ANOVA's following significant dose $\times$ intensity interaction). A significant reduction in the effects of $1.0 \mathrm{mg} / \mathrm{kg}$ DOI was noted in Block 3 vs. Block 2 for $15 \mathrm{~dB}$ trials (\#significant effect of block, $p<.05$, after significant block $\mathrm{x}$ intensity interaction for this dose).

PREPULSE trials independent of changes in PULSE startle magnitude-for $15 \mathrm{~dB}$ prepulses (vehicle vs. $1.0 \mathrm{mg} / \mathrm{kg}$ DOI: significant prepulse intensity $\times$ dose interaction $(\mathrm{F}=4.02, \mathrm{df}=2,30, \mathrm{p}<.03)$; for $15 \mathrm{~dB}$ trials, vehicle vs. $1.0 \mathrm{mg} / \mathrm{kg}$ DOI: $\mathrm{F}=10.40, \mathrm{df}=1,31$, $p<.005)$.

A comparison of the adult SDH males from Experiment $1(n=34)$ and the pup SDH males $(n=41)$ was used to assess developmental changes in PPI and DOI sensitivity. Dose-dependent effects of DOI on PPI followed very similar patterns in adults and 17-day old pups (Figure 1, top vs. Figure 3, top). Because findings above demonstrated a significant diminution of DOI effects on PPI in Block 3 vs. Block 2, data were segregated by trial block. In Block 2, ANOVA with dose and age as between subject factors revealed a significant effect of age $(\mathrm{F}=46.06, \mathrm{df}=1,65, p<.0001)$ and DOI dose $(\mathrm{F}=$ $8.30, \mathrm{df}=4,65, p<.0001)$, but no significant age $\times$ DOI interaction $(\mathrm{F}=1.48, \mathrm{df}=4,65, \mathrm{~ns})$. There was a significant effect of prepulse intensity $(\mathrm{F}=50.43, \mathrm{df}=2,130, p<$ .0001 ), and a significant interaction of prepulse inten- sity $\times$ age $(\mathrm{F}=4.19, \mathrm{df}=2,130, p<.02)$, but no other significant 2- or 3-way interactions.

In Block 3, ANOVA revealed a significant effect of age $(\mathrm{F}=28.87, \mathrm{df}=1,65, p<.0001)$ and DOI dose $(\mathrm{F}=3.93$, $\mathrm{df}=4,65, p<.007)$, but no significant age $\times$ DOI interaction $(\mathrm{F}=1.49, \mathrm{df}=4,65, \mathrm{~ns})$. There was a significant effect of prepulse intensity ( $\mathrm{F}=56.27, \mathrm{df}=2,130, p<.0001)$, but no other significant 2- or 3-way interactions. In pups, as in adults, the PPI-disruptive effects of the high dose of DOI $(1.0 \mathrm{mg} / \mathrm{kg})$ were significantly diminished in Block $3 \mathrm{vs}$. Block 2: ANOVA revealed a near-significant effect of block $(\mathrm{F}=4.06, \mathrm{df}=1,7, p<.085)$, and a significant block $\times$ intensity interaction $(\mathrm{F}=4.08, \mathrm{df}=2,14, p<.05)$; post hoc analysis revealed that this effect reached significance for $15 \mathrm{~dB}$ trials $(\mathrm{F}=6.77 \mathrm{df}=1,7, p<.04)$.

The similar dose-response "profiles" across development were evident despite the fact that PPI levels in pups were significantly lower than in adults (as previously reported by Martinez et al. (2000)), and thus "compressed" greatly to floor levels, particularly for 5 $\mathrm{dB}$ prepulses. 
Startle Magnitude and Habituation in SDH Pups. ANOVA with dose of DOI and sex as between subject factors revealed a significant effect of $\operatorname{sex}(\mathrm{F}=5.54, \mathrm{df}=$ $1,75, p<.025)$ with startle response in females being smaller than in males (Table 2). There was a significant effect of trial block ( $\mathrm{F}=14.64, \mathrm{df}=1,75, p<.0005)$, and a significant interaction of block $\times$ DOI $(\mathrm{F}=2.74, \mathrm{df}=$ $4,75, p<.05)$. This latter interaction reflected the fact that habituation was evident for some (e.g., $0.25 \mathrm{mg} /$ $\mathrm{kg}$ ) but not all (e.g., $0.1 \mathrm{mg} / \mathrm{kg}$ ) doses of DOI. Habituation was also observed in the significant reduction of startle magnitude between Blocks 1 and $4(\mathrm{~F}=113.34$, $\mathrm{df}=1,75, p<.0001)($ Table 2$)$.

NoStim Activity. DOI significantly increased gross motor activity in pups, as it did in adults (Table 2). ANOVA with dose and sex as between subject factors revealed a significant effect of DOI $(\mathrm{F}=2.50, \mathrm{df}=4,85$, $p<.05)$, no significant interaction of sex $\times \mathrm{DOI}(\mathrm{F}<1)$, and no other significant interactions.

\section{DISCUSSION}

The present study assessed developmental and strain differences in the effects of DOI on sensorimotor gating in rats. While administration of DOI attenuated \%PPI similarly in both $\mathrm{SDH}$ and $\mathrm{WH}$ adult male rats, DOI produced an unambiguous disruption of sensorimotor gating only in SDH rats. This conclusion reflects the fact that DOI exhibited both startle-reducing and PPIreducing effects in $\mathrm{WH}$ rats; post hoc strategies using "matched" dose groups provided some support for the notion that these two effects might be statistically, and presumably neurobiologically, separable.

In previous studies, we have reported that similar strain differences in the sensitivity to the PPI-disruptive effects of the DA agonist apomorphine were "constitutional" and not acquired, since they were evident very early in development, in rats reared in neighboring cages in the same room (Swerdlow et al. 2000). The fact that SDH pups in the present study manifest their adult phenotype by day 17 in males suggests that the sensitivity to the sensorimotor gating-disruptive effects of DOI is also a "constitutional" trait in this strain. It is important to note that this strain difference cannot be assumed to apply to $\mathrm{SD}$ and $\mathrm{W}$ rats from all suppliers: our previous studies have demonstrated differences in the sensitivity to the PPI-disruptive effects of DAergic agents within a single strain, across suppliers (e.g., Harlan (USA) vs. Bantin-Kingman (UK)) (Swerdlow et al. 2000); others have noted similar intrastrain differences in responsivity to serotonergic agents (Hitchcock et al. 1999).

The sensitivity to DOI disruption of sensorimotor gating in male pups is indicative of early functionality of specific brain systems that regulate this process. This early sensitivity to drug induced disruption of sensorimotor gating has also been seen in SDH rats with PCP and apomorphine (Martinez et al. 2000), and occurs despite the fact that - as reported in this study, and previously (Martinez et al. 2000) - the amount of PPI clearly increases across development. Gating-disruptive effects of DOI in juvenile rats suggests that 5-HT2A regulation of sensorimotor gating in males is not dependent on adult patterns of forebrain innervation, puberty, or other processes of later maturation. DOI may regulate sensorimotor gating in adult rats at least in part via its actions within the ventral pallidum (Sipes and Geyer 1997), but it is not known whether this is the substrate responsible for DOI effects on sensorimotor gating in male pups.

DOI-induced disruption of PPI was not as clearly established in female SDH pups, although modest trends were observed. This apparent sex difference in early sensitivity of PPI to DOI might reflect limited power of this study, although the sample size for female pups $(n=$ 44) exceeded that for males $(n=41)$. Alternatively,

Table 2. Startle magnitude, habituation, and NO STIM activity in male and female SDH pups

\begin{tabular}{|c|c|c|c|c|c|c|c|}
\hline \multirow{2}{*}{$\begin{array}{l}\text { Dose DOI } \\
(\mathrm{mg} / \mathrm{kg})\end{array}$} & \multirow[b]{2}{*}{$N$} & \multicolumn{2}{|c|}{$\begin{array}{l}\text { Startle Magnitude } \\
\text { (mean (SEM)) }\end{array}$} & \multicolumn{2}{|c|}{$\begin{array}{l}\text { Habituation (startle magnitude } \\
\text { (mean (SEM)) in Blocks } 1 \text { and } 4)\end{array}$} & \multirow{2}{*}{$\begin{array}{c}\% \\
\text { Habituation }\end{array}$} & \multirow{2}{*}{$\begin{array}{c}\text { NO STIM } \\
(\text { mean }(\text { SEM) })\end{array}$} \\
\hline & & Block 2 & Block 3 & Block 1 & Block 4 & & \\
\hline \multicolumn{8}{|l|}{ Males } \\
\hline Veh & 9 & $54.40(10.47)$ & 50.68 (9.73) & 102.42 (11.92) & $53.41(9.92)$ & 43.21 & $0.198(.124)$ \\
\hline 0.10 & 8 & $64.86(8.85)$ & $61.22(12.07)$ & 91.19 (11.62) & $63.00(10.86)$ & 31.32 & $0.057(.038)$ \\
\hline 0.25 & 8 & $68.27(8.60)$ & $49.73(8.64)$ & $103.44(14.99)$ & $57.21(10.71)$ & 44.03 & $0.543(.398)$ \\
\hline 0.50 & 8 & $59.81(8.13)$ & $61.27(10.02)$ & $103.22(12.40)$ & $56.79(10.46)$ & 35.49 & $0.631(.128)$ \\
\hline 1.00 & 8 & $59.95(5.74)$ & $58.19(8.16)$ & $103.13(12.44)$ & $53.04(4.50)$ & 44.59 & $0.512(.174)$ \\
\hline \multicolumn{8}{|l|}{ Females } \\
\hline Veh & 9 & $57.24(6.58)$ & $47.56(6.25)$ & 102.69 (7.49) & 64.85 (9.93) & 37.5 & $0.052(.031)$ \\
\hline 0.10 & 9 & $27.43(5.52)$ & $33.44(7.22)$ & $74.53(16.51)$ & $31.30(7.53)$ & 46.78 & $0.200(.110)$ \\
\hline 0.25 & 9 & $50.01(10.09)$ & $35.49(6.31)$ & 89.33 (15.69) & $25.93(4.51)$ & 65.53 & $0.094(.034)$ \\
\hline 0.50 & 8 & $56.95(12.39)$ & 48.05 (12.02) & 46.01 (16.27) & $40.00(6.85)$ & 47.02 & $0.480(.146)$ \\
\hline 1.00 & 9 & $62.08(6.66)$ & $48.32(6.35)$ & $97.06(12.64)$ & $46.63(6.50)$ & 34.75 & $0.338(.075)$ \\
\hline
\end{tabular}


these sex differences might reflect fixed traits, or might be limited to this point of early development. Both female and male pups showed an increase in NoStim activity after DOI treatment. In other words, evidence for central actions of DOI were evident in both sexes at this age. Ongoing studies with PPI are examining sex differences in DOI sensitivity in adult rats, which must be interpreted in the context of estrous cyclicity of PPI in adult female rats (Koch 1998). Others have detected sex differences in basal and drug-disrupted PPI in Wistar rats (Lehmann et al. 2000).

The present study also revealed a time- and dosedependent reversal of the sensorimotor gating-disruption by DOI in SDH adults and pups. Early in its time course, DOI clearly reduced PPI, and this was a consequence of a reduction in the startle-inhibiting properties of prepulses in SDH rats. Later in its time course, this effect waned, and was significantly diminished at higher doses of DOI. This time dependent biphasic response of DOI may be explained by a rapid desensitization of the 5-HT2A receptor at higher doses, an autoreceptor effect, or other interacting effects of anatomically separate serotonergic systems. The mechanism(s) responsible for this time dependent biphasic response are functional early in development, and remain functional into adulthood.

Finally, the present findings underscore the importance of assessing raw startle magnitude on PULSE and PREPULSE trials, in interpreting the physiological basis for drug-induced changes in percent prepulse inhibition. While WH vs. SDH strain differences were not evident in reduced values of \%PPI, inspection of raw startle scores revealed clear strain differences in the processes responsible for DOI-induced changes in PPI. A simple loss of sensorimotor gating can be inferred by a reduction in the reflex-inhibiting effectiveness of a prepulse, independent of changes in startle magnitude. In the present study, such effects of DOI were evident in male SDH adult rats, but not in male WH adult rats.

\section{ACKNOWLEDGMENTS}

This research was supported in part by grants from the National Institutes of Mental Health (MH-01436, MH-53484, MH42228) and Drug Abuse (DA-02925), and the Department of Veterans Affairs VISN 22 Mental Illness Research, Education and Clinical Centers (MIRECC). MAG has an equity interest in SD Instruments.

\section{REFERENCES}

Bolino F, Di Michele V, Di Cicco L, Manna V, Daneluzzo E, Cassachia M (1994): Sensorimotor gating and habituation evoked by electrocutaneous stimulation in schizophrenia. Biol Psychiatry 36:670-679
Braff DL, Stone C, Callaway E, Geyer MA, Glick ID, Bali L (1978): Prestimulus effects on human startle reflex in normals and schizophrenics. Psychophysiology 15:339-343

Castellanos FX, Fine EJ, Kaysen DL, Kozuch PL, Hamburger SD, Rapoport JL, Hallett M (1996): Sensorimotor gating in boys with Tourette's syndrome and ADHD: Preliminary results. Biol Psychiatry 39:33-41

Davis M, Mansbach RS, Swerdlow NR, Braff DL, Geyer MA (1990): Apomorphine disrupts prepulse inhibition of acoustic startle in rats. Psychopharm 102:1-4

Dulawa SC, Hen R, Scearce-Levie K, Geyer MA (1997): Serotonin $1 \mathrm{~B}$ receptor modulation of startle reactivity, habituation, and prepulse inhibition, in wild-type and serotonin 1B receptor knockout mice. Psychopharmacology 132:125-134

Grillon C, Ameli R, Charney DS, Krystal J, Braff DL (1992): Startle gating deficits occur across prepulse intensities in schizophrenic patients. Biol Psychiatry 32:939-943

Hitchcock JM, Selk DE, Wettstein JG, Rush DK (1999): Intrastrain differences in the disruption of prepulse inhibition in rats by PCP, DOI, and 7-OH-DPAT. Schizophr Res 36:115

Kehne JH, McCloskey TC, Taylor VL, Black CK, Fadayel GM, Schmidt CJ (1992): Effects of serotonin releasers 3,4-methylenedioxymethamphetamine (MDMA), 4chloroamphetamine (PCA), and fenfluramine on acoustic and tactile startle reflexes in rat. J Pharmacol Exp Ther 260:78-89

Kehne JH, Padich RA, McCloskey TC, Taylor VL, Scmidt CJ (1996): 5-HT modulation of auditory and visual sensorimotor gating. I. Effects of 5-HT releasers on sound and light prepulse inhibition in Wistar rats. Psychopharmacology 124:95-106

Kinney GG, Wilkinson LO, Saywell KL, Tricklebank MD (1999): Rat strain differences in the ability to disrupt sensorimotor gating are limited to the dopaminergic system, specific to prepulse inhibition, and unrelated to changes in startle amplitude or nucleus accumbens dopamine receptor sensitivity. J Neurosci 13:5644-5653

Koch M (1998): Sensorimotor gating changes across the estrous cycle in female rats. Physiol Behav 64:625-628

Lehmann J, Pryce CR, Feldon J (2000): Lack of effect of an early stressful life event on sensorimotor gating in adult rats. Schizophr Res 41:365-371

Mansbach RS, Geyer MA, Braff DL (1988): Dopaminergic stimulation disrupts sensorimotor gating in the rat. Psychopharmacology 94:507-514

Mansbach RS, Geyer MA (1989a): Effects of phencyclidine and phencyclidine biologs on sensorimotor gating in rat. Psychopharmacology 94:507-514

Mansbach RS, Braff DL, Geyer MA (1989b): Prepulse inhibition of the acoustic startle response is disrupted by N-ethyl-3,4-methylenedioxy-amphetamine (MDEA) in the rat. Eur J Pharmacol 167:49-55

Mansbach RS, Geyer MA (1991): Parametric determinants in pre-stimulus modification of acoustic startle: Interaction with ketamine. Psychopharmacology 105:162-168

Martinez DL, Geyer MA (1997): Characterization of the disruptions of prepulse inhibition and habituation of startle induced by alpha-ethyltryptamine. Neuropsychopharmacology 16:246-255 
Martinez ZA, Halim ND, Oostwegel JL, Geyer MA, Swerdlow NR (2000): Ontogeny of phencyclidine and apomorphine-induced startle gating deficits in rats. Pharmacol Biochem Behav 65:449-457

McGhie A, Chapman J (1961): Disorders of attention and perception in early schizophrenia. Br J Med Psychol 34:102-116

Ornitz EM, Hanna GL, de Traversay J (1992): Prestimulationinduced startle modulation in attention-deficit disorder and nocturnal enuresis. Psychophysiology 29:437-451

Rigdon GC (1990): Differential effects of apomorphine on prepulse inhibition of acoustic startle reflex in two rat strains. Psychopharmacology (Berl) 102:419-421

Rigdon GC, Weatherspoon J (1992): 5HT1A receptor agonists block prepulse inhibition of the acoustic startle reflex. J Pharmacol Exp Ther 263:486-493

Sipes TA, Geyer MA (1994): Multiple serotonin receptor subtypes modulate prepulse inhibition of the startle response in rats. Neuropsychopharmacology 33:441448

Sipes TA, Geyer MA (1995a): 8-OH-DPAT disruption of prepulse inhibition in the rat: Localization of site action with WAY 100,135. Psychopharmacology 117:41-48

Sipes TE, Geyer MA (1995b): DOI disruption of prepulse inhibition of startle in the rat is mediated by $5-\mathrm{HT} 2 \mathrm{~A}$ and not by 5 HT2C receptors. Behav Pharmacol 6:839-842

Sipes TE, Geyer MA (1996): Functional behavioral homology between rat $5 \mathrm{HT} 1 \mathrm{~B}$ and guinea pig $5 \mathrm{HT} 1 \mathrm{D}$ receptors in the modulation of prepulse inhibition of startle. Psychopharmacology 125:231-237

Sipes TE, Geyer MA (1997): DOI disrupts prepulse inhibition of startle in rats via 5-HT2A receptors in the ventral pallidum. Brain Res 761: 97-104

Swerdlow NR, Geyer MA, Braff DL, Koob GF (1986): Central dopamine hyperactivity in rats mimics abnormal acoustic startle in schizophrenics. Biol Psychiatry 21:23-33

Swerdlow NR, Benbow CH, Zisook S, Geyer MA, Braff DL (1993): A preliminary assessment of sensorimotor gating in patients with obsessive compulsive disorder (OCD). Biol Psychiatry 33:298-301

Swerdlow NR, Braff DL, Taaid N, Geyer MA (1994): Assessing the validity of an animal model of sensorimotor gating deficits in schizophrenic patients. Arch Gen Psychiatry 51:139-154

Swerdlow NR, Geyer MA (1993): Prepulse inhibition of acoustic startle after lesions of the pedunculopontine nucleus. Behav Neuroscience 107:104-117

Swerdlow NR, Paulsen J, Braff DL, Butters N, Geyer MA, Swenson MR (1995): Impaired prepulse inhibition of acoustic and tactile startle in patients with Huntington's disease. J Neurol Neurosurg Psychiatry 58:192-200

Swerdlow NR, Geyer MA (1998): Using an animal model of deficient sensorimotor gating to study the pathophysiology and new treatments of schizophrenia. Schizophr Bull 24:285-302

Swerdlow NR, Varty GB, Geyer MA (1998): Discrepant findings of clozapine effects on prepulse inhibition of startle: Is it the route or the rat? Neuropsychopharmacology 18:50-56

Swerdlow NR, Martinez Z, Hanlon FM, Platten A, Farid M, Auerbach P, Braff DL, Geyer MA (2000): Towards understanding the biology of a complex phenotype: Rat strain and substrain differences in the sensorimotor gating-disruptive effects of dopamine agonists. Journal of Neuroscience 20:4325-4336

Varty GB, Higgins GA (1994): Differences between three rat strains in sensitivity to prepulse inhibition of an acoustic startle response: Influence of apomorphine and phencyclidine pretreatment. Psychopharmacology 8: 148-156 